Geomatics, Landmanagement and Landscape No. 4 • 2018, 29-47

\title{
A SHORT REVIEW OF INTERPOLATION METHODS USED FOR TERRAIN MODELING
}

\author{
Robert Gradka, Andrzej Kwinta
}

\begin{abstract}
Summary
The determination of landforms of the terrain depends on a number of procedures. In general, all these procedures can be subdivided into two groups. The first group consists of measurement activities related to obtaining real-life data. The second group comprises operations related to the processing of results, in order to obtain the imaging. The measurements of the terrain and its landforms are discrete. Cartographic images are continuous. In order to get a map of 3D measurements, contours need to be interpolated. In this publication, four of the many interpolation methods were selected for presentation: Global Polynomial, Inverse Distance, Radial Basis Function, and Kriging. The example of the measurement results for a syncline (a subsidence trough) is used in order to illustrate the comparison between the modes of operation of particular methods.
\end{abstract}

\section{Keywords}

Interpolation Method • Digital Terrain Modeling • subsidence analysis

\section{Introduction}

Land surface - or the terrain - is a variable physical object. Various natural and anthropogenic processes shaped the configuration of this surface. Of course, natural phenomena of a broad spatial and temporal range have the greatest impact on the shaping of the Earth's surface, but human activity is also of significance in this respect. The change in configuration of the terrain points is a continuous process, with varying degrees of dynamics [Borchers and Carpenter 2014].

In many areas of science and practice, knowledge about the terrain is indispensable. The determination of the shape of the land's surface is the subject of the surveyors' activities. There are many different measurement methods that make it possible to determine the shape of the terrain [Wilson 2012, Buśko et al. 2014]. Originally, these included classical surface levelling methods (technical levelling with the use of distributed points method, reticular method, and tachymetric measurement). Nowadays, methods using scientific advances of the last decades are increasingly popular, such as approaches that apply GNSS levelling, and above all, photogrammetric methods. 
State-of-the-art digital photogrammetry facilitates acquisition of large amounts of data on large areas. Airborne laser scanning and low-ceiling photogrammetry also provide large sets of measurement data.

The measurement of the features in the terrain is just one step in the acquisition of data. An equally important role in obtaining the final image of the terrain features is the processing of the measurement data and their modelling. As a result of these operations, an image is obtained in the format of an isoline map or a spatial model. The selection of the appropriate method for the development of the results obtained from the measurements is of great importance for the final output. Depending on the choice of data interpolation method, and the choice of its parameters, one may obtain different results [Grzelak and Kwinta 2012]. Generally, the obtained results will have similar features, but they may differ significantly in the details.

The present publication will provide an overview of methods for interpolating surface contours, as illustrated with the example of selected theoretical solutions. The formal foundations of particular methods will be presented, along with their comparison.

\section{Interpolation methods}

In the subject literature, we find many different interpolation algorithms pertaining to various features. This issue applies to all fields of science in which measurements are conducted. Measurable features can be of different character, and they can be obtained in a variety of ways. Generally, given measurement points in the space of $\mathbf{R}^{3}$, we are interested in imaging the results from the measurements in a graphical format (for instance, on the map). The results of measurements are sets of discrete points, whereas graphical presentation on maps requires continuous data sets. Hence the need to replace a discrete set with functions (sets of functions), which would allow us to determine the value of the feature beyond the measurement point. This procedure is referred to as approximation. Depending on the theoretical foundation behind the selection of the approximation function, the following methods are distinguished [Ralston 1965]:

- Extract or interpolatory approximations - an approximation function should pass through all the points on the basis of which it had been determined,

- Least-squares approximations - the approximation function minimizes the distance between the set of the measured points and the set of theoretical points,

- Minimum/ maximum error approximations - selecting a function from among the possible solutions for which the biggest mismatch error will be the smallest.

Over the years, many different interpolation algorithms have been developed, from the simplest linear methods to very complex nonlinear methods. Among the frequently used interpolation methods, the following can be listed:

- Linear,

- Kriging, 
- Global Polynomial,

- Local Polynomial,

- Radial Basis Function,

- Inverse distance,

- Modified Shepard's,

- Minimum curvature,

- Nearest-neighbour.

Among those listed, four selected interpolation methods will be presented in more detail below.

\subsection{Global Polynominal Interpolation (GP)}

This particular method of interpolation consists in matching a smooth surface, defined by a mathematical (polynomial) function, to the input data points. Given any $n+1$-element set of points $\left\{\left(x_{0}, y_{0}\right),\left(x_{1}, y_{1}\right), \ldots,\left(x_{n}, y_{n}\right)\right\}$ in which $\boldsymbol{x}_{i}$ are different in pairs, there is a polynomial of the $n$ degree at the most, whose graph goes through these points. The problem of finding this polynomial is called polynomial interpolation. The interpolation can serve to approximate functions using polynomials. Exactly one interpolation polynomial exists. It follows that if two polynomials of a degree not greater than $n$ adopt the same values in $n+1$ points, then they are equal. To give two examples, Lagrange or Newton polynomials [Sauer 2006] can be used for interpolation.

The global polynomial data interpolation method is classified among inaccurate interpolators, because the mathematical function (in the form of a plane) rarely passes through all the actual measured points. Some points will be above the plane, and others will be below it, but if you add the number of points above the plane and the number of points below it, their sums should be similar.

Each surface in this method is obtained by the method of least squares, hence the differences between the surface and the points are the smallest [Draper and Smith 1981].

a)

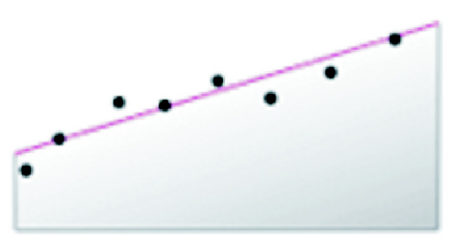

b)

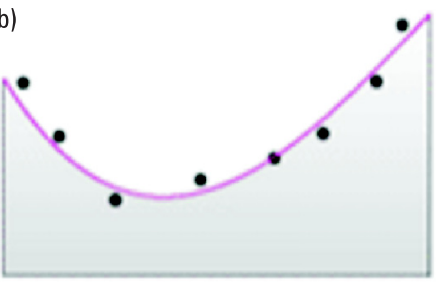

Fig. 1. Surface matching according to the GP method: a) plane matching, b) second degree polynomial matching 
Due to the limitations resulting from the degree of the polynomial that can be used, this method is subject to a number of restrictions. Its possible applications are therefore limited. The global polynomial interpolation slowly creates a different surface, using low-order polynomials that can possibly describe a physical process (for instance, air pollution or wind direction). However, it should be noted that the more complex the polynomial, the more difficult it is to assign physical meaning to it. In addition, the calculated surfaces are very susceptible to the occurrence of disturbances in the extreme values (i.e. extremely high and extremely low values), especially at the edges. This method is mainly used for:

- Surface matching to the sample of points, when the surface changes slowly from region to region in the area of interest (for instance, pollution in the industrial area).

- Research into and/or removal of long-range results or effect of global trends. In such circumstances, the technique is often referred to as trend surface analysis.

\subsection{Inverse Distance Method (IDW)}

This method is often called Inverse Distance Weighted to a Power (IDW). It is assumed that the influence of the measurement points decreases with the distance raised to a power. The larger the exponent, the less important are the further measurement points [Magnuszewski 1999]. The method consists in assigning a value to a point in space, which is the result of interpolation of values from measurement points in a previously designated neighbourhood. Unknown variable size at any point is estimated by calculating a weighted average of observations in the environment. The observation weights are inversely proportional to the distance between the measurement point and the interpolated point. This dependence can be either linear or raised to the power, most often of 2 or 3 . The selection of a circle with a given radius as the neighbourhood can be defined independently [Watson 1992, Burrough and McDonnell 1998]. Potentially, all measured points can be used for calculations. Because the points that are located further are given a lower weight, the economics of calculations indicate the need to set a radius within which we search for points for the analysis in the given case.

This method is based on the formal assumption that those points, which are close to each other, are more similar than those, which are further apart. In order to determine the value for any unmeasured location, IDW uses the measured values surrounding the predicted location. The measured values of the points, which are the closest to the estimated position of the point have a greater impact on the obtained values than those, which are further away. The Inverse Distance Method assumes that each measured point exerts a local influence, which decreases with distance. This gives higher weights to the points closest to the predicted location, and the weights decrease depending on the distance, hence the distances are described as inversely weighted (Fig. 2).

The red crosses in Figure 2 are points with known values (results of height measurements) $-z_{i}$ determined at specific locations of $x_{i}, y_{i}$. The black cross is a point with a specific location $x, y$ and an unknown (interpolated) value of the variable $z(x, y)$. 
Determining the value of the variable $z$ is based on finding the distances to the measured points $\left(d_{i}\right)$, and then assigning weights $\left(w_{i}\right)$ to the measured points in order to determine the given characteristics (in our case, the height) [Franke 1982, Davis 1986].

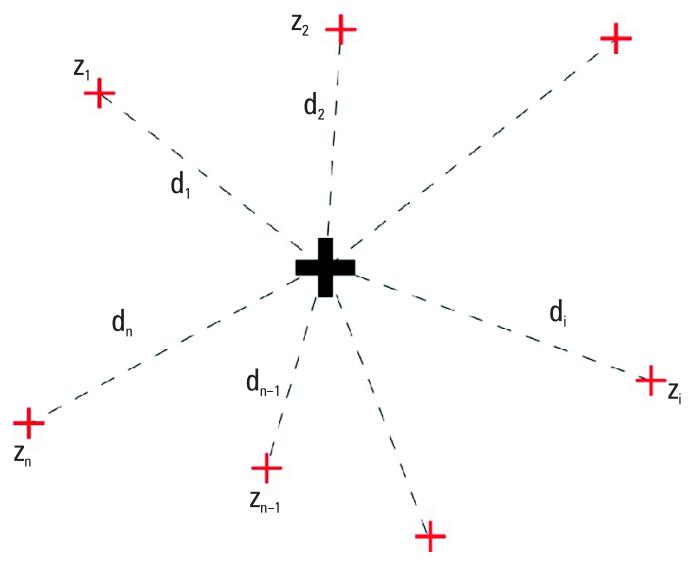

Fig. 2. A sample diagram describing the Inverse Distance Weighting method, or IDW

According to the above, we can write the following formula for the value of the designated weight for each of the points:

$$
w_{i}=\frac{1}{d_{i}^{p}}
$$

and the formula for the interpolated value of the $(z)$ variable:

$$
z= \begin{cases}\frac{\sum_{i=1}^{n} w_{i} z_{i}}{\sum_{i=1}^{n} w_{i}} & \text { if } d_{i} \neq 0 \\ z_{i} & \text { if } d_{i}=0\end{cases}
$$

As mentioned earlier, the weights are proportional to the reciprocal distance (between the data points and the predicted location) raised to the power $p$. As a result, as the distance increases, the weights decrease very quickly. The intensity of the weight decrease depends on the value of $p$ (Fig. 3). If $p=0$, then there is no drop in the distance, because each weight is the same, and the predicted value will be the average of the data values in the neighbourhood of the search. With the increase in the value of $p$, the weights to distant points decrease rapidly. If the value of $p$ is very high, then only the points in the immediate neighbourhood will affect the predicted value. 


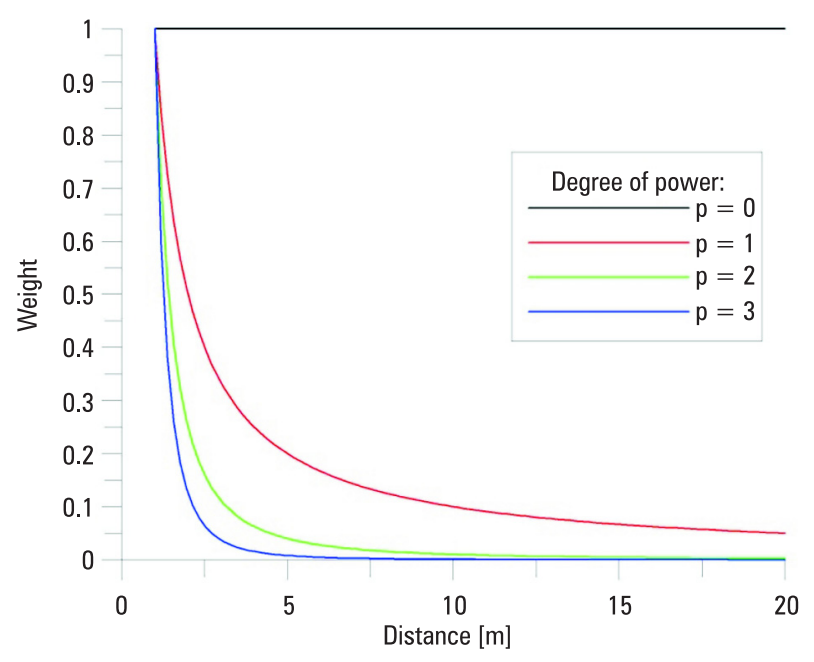

Fig. 3. Diagram showing the relationship between weight and distance

The analysis uses values of powers greater than or equal to 1 . The value of power $p=2$ is used by default, although there is no theoretical justification for choosing this value as opposed to others, and the effect of changing the value of $p$ should be examined by viewing the output data, and analysing the cross statistics.

When evaluating the method, it can be concluded that it is computationally simple, using the intuitively understandable principle of similarity (or dependence) between point values decreasing in proportion to the increase in distance. Interpolation performed with this method works well when the measurement points are numerous and relatively evenly spaced. The parameters selected during the interpolation have a significant impact on the calculation result - including for instance the selection of the appropriate size of "neighbourhoods" taken into account for interpolation. Choosing "neighbourhoods" which are too small can result in gaps in the interpolated surface, in locations where it is not possible to estimate the parameter value. The method is relatively simple and easy to elaborate, and it is quite accurate, because the value determined at the measurement point is equal to the value measured at this point, however, its main drawback is that the interpolated values must be within the range determined by the measurement points.

\subsection{Radial Basis Functions method (RBF)}

The interpolation method using radial basis functions actually contains a diverse group of accurate data interpolation methods. This is a function whose value depends on the distance to a specific point. RBF is characterized by the fact that the interpolated surface must pass through each measurement point [Sarra 2009]. 
There are five basic types of radial basis functions:

- Thin-plate spline,

- Spline with tension,

- Completely regularized spline,

- Multiquadric function,

- Inverse multiquadric function.

Each of the above functions has a different shape, and as a result, it interpolates the surface in a slightly different way. RBF methods constitute a kind of artificial neural networks, and each of them has its own parameter, which controls the surface smoothness. For all methods, with the exception of inverse multiquadric method, the higher the parameter value, the smoother maps can be obtained. In the case of inverse multiquadric method, the lower the value, the better the result we get.

In terms of data adaptation capacity, and in order to create a smooth surface, the multiquadric method is widely used and considered by many to be the best [Chenoweth 2009, Mongillo 2011]. This method is an alternative to Kriging [Hardy 1990]. It is a representation of an irregular surface using many linear functions connecting the node with data points. The function is expressed by the formula (3):

$$
V(h)=\sqrt{d^{2}+R^{2}}
$$

where:

$d$ - distance of the point from the grid node,

$R^{2}$ - smoothing parameter, defined by the user.

The default value of the $R^{2}$ parameter is calculated from the formula (4) [Carlson \& Foley 1991]:

$$
R^{2}=\frac{L^{2}}{25 N}
$$

where:

$L$ - the length of the diagonal in the data range,

$N$ - the number of measurement points.

RBF are very flexible, passing through all the measured values of samples, while minimizing the total curvature of the surface. The basis function determines which plane (surface) matches in-between the values.

RBF methods, being exact interpolators, differ from global and local polynomial interpolators, in that they are inaccurate interpolators and they do not require for the interpolated surface to pass through the measurement points. Comparing the RBF to the IDW inverse distance method (which is accurate and faithful): IDW will never assume an interpolated value above the maximum or below the minimum value of the measured points (Fig. 4a), whereas RBF will do that (that is, it will predict the values below or above, Fig. 4b). 

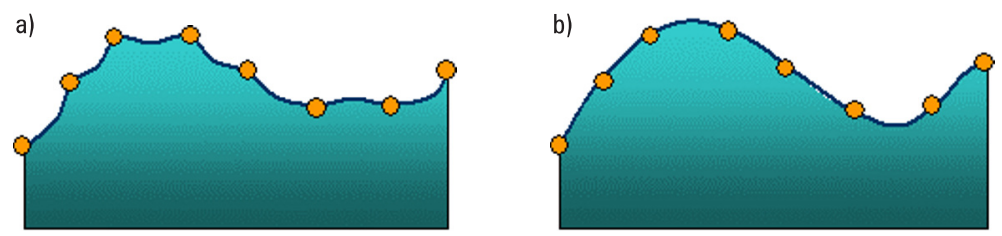

Source: www.help.arcgis.com

Fig. 4. Interpolation result for: a) IDW method, b) RBF method

There are many ways in which it is possible to predict the shape of the surface between the measured points. For example, a surface can be forced to create thinplate splines. It is also possible to determine, how much the surface can spline with tension.

These methods are primarily used in calculating smooth surfaces from a large number of point data. The functions produce good results on slightly differentiated surfaces, such as the terrain with small differences in height. These techniques are unsuitable wherever there are large changes in surface values at a short horizontal distance and/or whenever it is suspected that the sample data is susceptible to measurement errors or uncertainties.

\subsection{Kriging method (KRIG)}

Geostatistical methods are now widely used in analysing various measured attributes in Earth sciences. They are used primarily in two cases:

- when the attributes of measurement data are known, including: the accuracy, density and distribution of measurement points as well as the quality of surface modelling,

- when it is necessary to obtain information in the processes of modelling the distribution of features.

Geostatistical analysis also determines the impact of surrounding points on the point that is being interpolated, and directional variability solves the problem of determining the number of measurement points that affect that particular point [Marmol 2002].

Isoline maps are one of the most frequently used cartographic forms of presenting information about the given area. From among different estimation formulas, the geostatistical Kriging technique is coming to the fore. There are many versions of Kriging [Namysłowska-Wilczyńska 2006], such as: Ordinary, Simple, Block, Point, and others. Ordinary Kriging is commonly used in geostatistics, and in field studies (for instance, in geology, geophysics or geodesy) [Wackernagel 2003, Childs 2012]. This is the oldest, parametric (linear) version of the Kriging procedure. Due to the size of the object in which the estimation is made, two forms of Kriging are distinguished: Point and Block Kriging. When developing isoline maps, Point Kriging is used primarily [Kokesz 2010]. 
Ordinary Kriging is a group of geostatistical interpolations. It assumes the existence of spatial autocorrelation, that is the relationship between the distance of points and the degree of their similarity. According to this dependence, the values measured in the points close to each other should be more similar than those measured at more distant points [Wackernagel 2003, Childs 2012].

In the Ordinary Kriging method, the following assumptions are made [Zawadzki 2011]:

- the data are isotropic (they exhibit the same features in all directions of exploration),

- local averages are not closely correlated with the average of the entire sample population, and only average points from the local neighbourhood are selected when assessing the average,

- the sum of weights allocated to the samples is equal to 1 , so that when all values are equal to the constant, the estimated value is also equal to the constant.

According to the assumptions of Kriging, the spatial diversity of the variable (the so-called regional variable) can be divided into three main components:

- general trend of volatility of fixed-average data,

- local spatially randomized variability,

- spatially uncorrelated "noise" (resulting, for example, from measurement errors).

Thus, the spatial differentiation of the given variable contains a random element, and is not a simple mathematical relationship. It is described by statistical methods and presented in a diagram called a semivariogram, and it is a basic tool used for estimating and studying the structure of variability of the studied phenomena in geostatistics. Real measurements taken directly from the natural environment are most often used for semivariogram or variogram calculations.

The semivariogram (Fig. 5) is adapted to the data in such a way as to approximate the relationship between the distance of the points $(\mathrm{Lag})$ and the degree of their similarity $(\gamma)$ in the form of a linear function.

Modelling of the spatial structure of the measured points begins with an empirical semivariogram, calculated from the following equation for all location pairs separated by the distance of $\mathbf{h}$ :

$$
\gamma(h)=\frac{1}{2 N(h)} \sum_{i=1}^{N(h)} h_{i}^{2}
$$

where:

$N(h)$ - the number of observation pairs,

$h$ - the distance between the observations.

Formula (5) includes the calculation of the square of the difference between the paired values of the position of the points. Interpolation is made on the basis of measurement data and semi-variance values. 


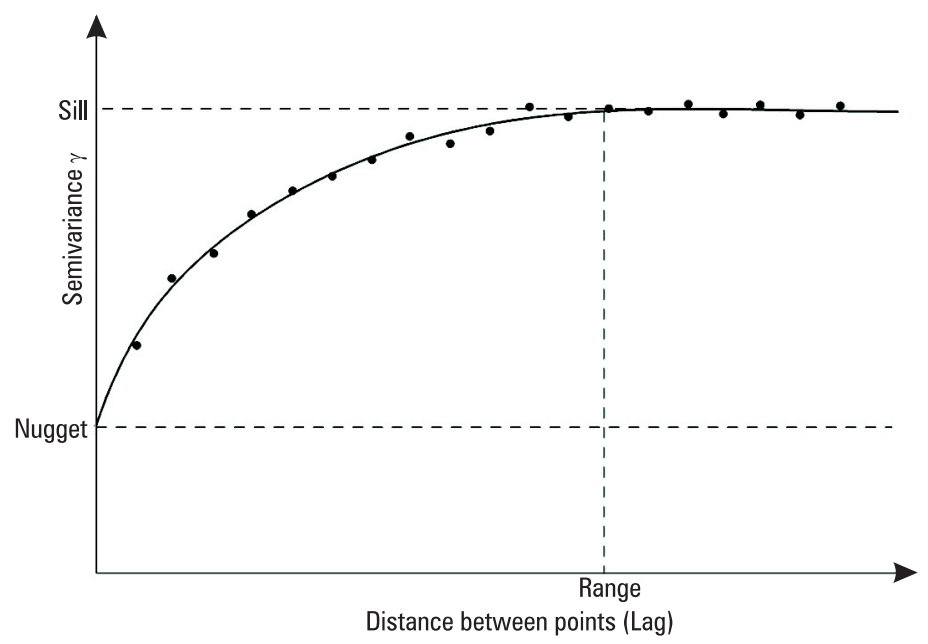

\section{Explanations}

Nugget (semi-variance value for a distance close to zero) is the amount of spatially uncorrelated "noise" that occurs when measuring the values of points located very close to each other. It may result, for example, from small measurement errors related to the accuracy of the measuring equipment itself.

Range (the distance above which semi-variance is a constant value) is the maximum range of the distance between the points at which a statistically significant correlation can be observed between the distance of points and the difference in their value.

Sill is the threshold value of the function corresponding to the range of impact determined by the range.

Source: Burrough and McDonnell [1998]

Fig. 5. Semivariogram - a sample diagram

Each pair of points has a unique distance, and there are often many pairs of points. If we were to plot all pairs quickly, the task would become unfeasible - hence, instead of plotting each pair, the pairs are grouped with respect to the distance from each other (Lag). This is based on the calculation of the average semi-variance for all pairs of points, which, for example, are more than 10 metres apart, but less than 15 metres apart.

The possibility of determining estimation errors, the determination of the statistical significance of the constructed interpolation surface and therefore also the uncertainty of the estimated data, constitute the most important advantages of geostatistical methods. Many authors [Robeson 1997, Mulugeta 1999, Wackernagel 2003, Childs 2012] have demonstrated that statistical methods (including Kriging) produce better results of spatial interpolation than deterministic methods.

Ordinary Kriging assumes that the spatial autocorrelation function is uniform in all directions (assumption of isotropy - irrespective of the direction). Unknown values are estimated by a weighted combination of values in the known points. Semivariogram is the basis for calculating the weights. Ordinary Kriging is one of the 
accurate and continuous methods of interpolation. It can be applied in both local and global varieties.

Some spatial surfaces cannot be modelled using deterministic methods (which use smooth mathematical functions), in particular if the data is insufficient (not dense enough) to model for instance ground water, gravity data, soil mapping, water toxicity, air pollution, bathymetric data, etc. Ordinary Kriging is a method that is useful for modelling phenomena that change continuously in space, including many natural phenomena. Values do not change by leaps and bounds; instead, they shift smoothly. The method offers a number of parameters that can be changed to best match the interpolating function to the data we have at our disposal. Spatial autocorrelation is determined by statistical methods, and the ability to determine the reliability of the conducted estimate turns out to be a great advantage of geostatistical methods.

\subsection{Comparison between different interpolation methods}

The theoretical solutions concerning interpolation presented in the above subsections are only some selected models. As mentioned above, there are many different solutions in the literature that can be used in practice.

The modelling of the terrain (the surface) and its transformations requires the selection of an appropriate method and a combination of appropriate calculation parameters. This depends on many factors, including the degree of land variety, but also the density of the measurement points. Below, in two tables, basic information about the presented interpolation methods has been summarized. Table 1 lists the data on the methods presented, taking into account the type of the model, the output surface, the necessary calculation time, and accuracy.

Table 1. List of calculation parameters for various interpolation methods

\begin{tabular}{|c|c|c|c|c|}
\hline Method & $\begin{array}{c}\text { Deterministic / } \\
\text { Stochastic }\end{array}$ & $\begin{array}{c}\text { Type of output } \\
\text { surface }\end{array}$ & $\begin{array}{c}\text { Time of calculation/ } \\
\text { Time of modelling }\end{array}$ & Interpolator accuracy \\
\hline $\begin{array}{c}\text { Global } \\
\text { Polynomial }\end{array}$ & Deterministic & Predicted & Quick / Quick & Non-accurate \\
\hline Inverse Distance & Deterministic & Predicted & Quick / Quick & Accurate \\
\hline $\begin{array}{c}\text { Radial Basis } \\
\text { Function }\end{array}$ & Deterministic & Predicted & $\begin{array}{c}\text { Moderately quick/ } \\
\text { Moderate }\end{array}$ & Accurate \\
\hline Kriging & Stochastic & $\begin{array}{c}\text { Predicted; } \\
\text { Probable; } \\
\text { Quantile }\end{array}$ & Moderate / Slow & $\begin{array}{c}\text { Accurate without } \\
\text { measurement errors; } \\
\text { Non-accurate with } \\
\text { measurement errors }\end{array}$ \\
\hline
\end{tabular}


In turn, Table 2 summarizes the basic advantages and disadvantages of each interpolation method. Of course, these are only selected advantages and disadvantages that are associated with the use of particular methods.

Table 2. List of advantages and disadvantages of the presented interpolation methods

\begin{tabular}{|c|c|c|}
\hline Method & Advantages & Disadvantages \\
\hline $\begin{array}{c}\text { Global } \\
\text { Polynomial }\end{array}$ & $\begin{array}{l}\text { - Several simple decision } \\
\text { parameters. } \\
\text { - Adjusting the surface to a sample } \\
\text { of points, when the surface slowly } \\
\text { changes from region to region } \\
\text { over the area of interest. }\end{array}$ & $\begin{array}{l}\text { - No evaluation of interpolation errors } \\
\text { - Interpolated surfaces may be too smooth. } \\
\text { - The boundary points have a large impact. } \\
\text { - Vulnerable to extreme (high and low) } \\
\text { values. }\end{array}$ \\
\hline $\begin{array}{c}\text { Inverse } \\
\text { Distance }\end{array}$ & $\begin{array}{l}\text { - Several simple decision } \\
\text { parameters. } \\
\text { - Extreme changes in the terrain } \\
\text { can be estimated (e.g. cliffs, } \\
\text { faults). } \\
\text { - Dense and even positioning of } \\
\text { points in space, with precise } \\
\text { interpolation. }\end{array}$ & $\begin{array}{l}\text { - No evaluation of interpolation errors. } \\
\text { - Produces contour lines around the } \\
\text { measured points. } \\
\text { - It is not possible to estimate values above } \\
\text { or below the maximum and minimum } \\
\text { values. } \\
\text { - Not suitable for interpolation of areas } \\
\text { with very diverse sculpture (e.g. in } \\
\text { mountain areas). }\end{array}$ \\
\hline $\begin{array}{l}\text { Radial Basis } \\
\text { Function }\end{array}$ & $\begin{array}{l}\text { - Flexible and automatic, with some } \\
\text { decision parameters. } \\
\text { - Useful for estimating the } \\
\text { maximum above, and the } \\
\text { minimum below the points. } \\
\text { - Produces smooth surfaces. }\end{array}$ & $\begin{array}{l}\text { - No evaluation of interpolation errors. } \\
\text { - Faults are not well represented due to the } \\
\text { smoothing effect. } \\
\text { - It does not work well when the points } \\
\text { are close to each other and have extreme } \\
\text { differences in value. }\end{array}$ \\
\hline Kriging & $\begin{array}{l}\text { - Very flexible. } \\
\text { - Enables the evaluation of } \\
\text { autocorrelation. } \\
\text { - Standard prediction errors can be } \\
\text { obtained. } \\
\text { - Many decision parameters. } \\
\text { - Exceeds the minimum and } \\
\text { maximum point values. }\end{array}$ & $\begin{array}{l}\text { Necessary series of analyses regarding } \\
\text { transformations, trends, models, } \\
\text { parameters and the neighbourhood. } \\
\text { - It does not pass through all the points, } \\
\text { and it causes interpolation of values } \\
\text { higher or lower than the measured } \\
\text { values. }\end{array}$ \\
\hline
\end{tabular}

The presented considerations are merely a substitute for a much broader topic. Nevertheless, this is a very important issue to consider when developing isoline maps of the terrain (the area) or its transformations.

\section{Examples}

For the practical comparison of interpolation methods, the results of two diametrically opposed measurements were used. In the first case, it is a small fragment of a larger measurement made by classical geodetic means, in a regular grid of measurement 
points. The second example uses the results of satellite imaging transformations of the surface area due to underground mining exploitation.

In the first example, a GNSS measurement of the area with a small regular slope was made. Measurements were carried out in a 10x5 metre grid. After processing, the measurement results were used for interpolation calculations. The results of contour interpolation are shown below, in Figures 6-9.

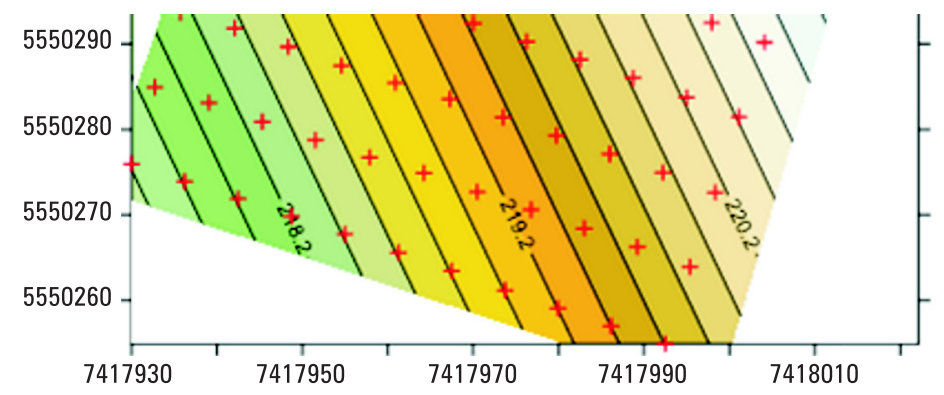

Fig. 6. An example of GP method application

The result of the global polynomials (GP) method is a smooth surface that represents gradual trends in a given area. Above, Figure 6 presents the result of interpolation of points measured by the GNSS technique, using the GP method.

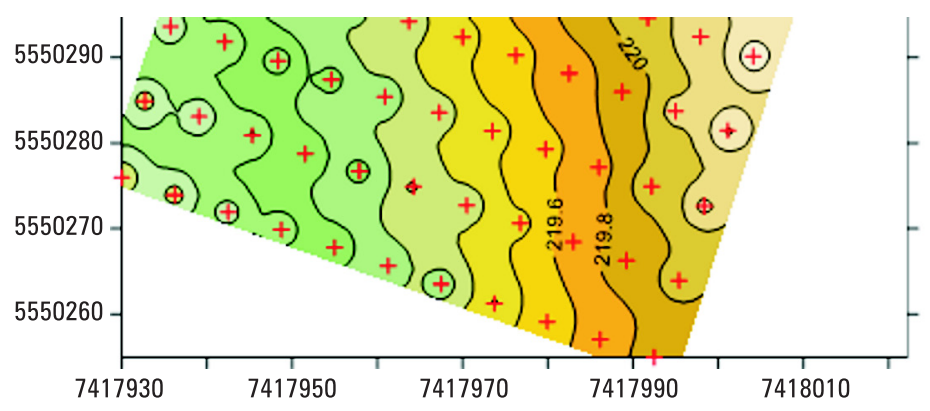

Fig. 7. Isolines obtained by applying the IDW method

Figure 7 shows an example of a contour model obtained from the IDW method. In order to produce this model, the smallest possible exponent $p$ was applied, equal to 2 . In the contour line drawing, we note concentric levels of the contours around the measurement points located at considerable distances in a rectangular grid. This is called the "free eyes" effect. This deficiency faded when reducing the exponent, and intensified 
when increasing it (for instance, to 3 or 4). Of course, this was related to the change in the range of impact of the measurement points depending on the size of the exponent. A larger exponent weakened the importance of further measurement points; therefore concentric circles were arranged around individual points [Szubert 2003].

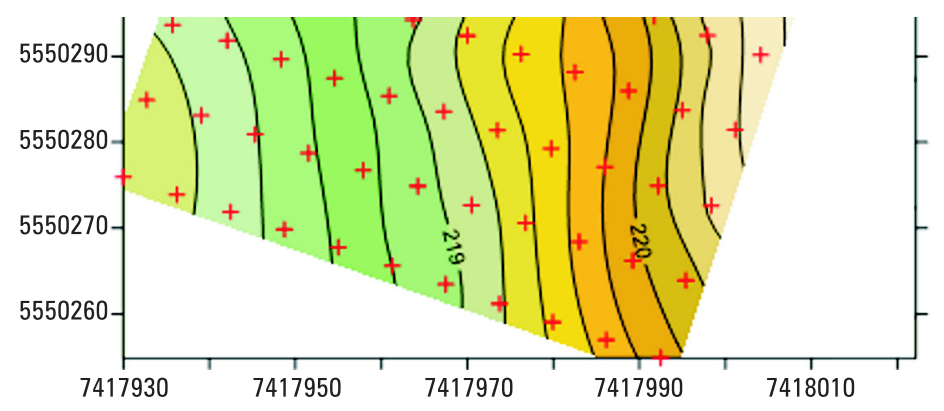

Fig. 8. An example of applying the RBF method

Radial Basis Functions make it possible to produce a surface (Fig. 8) that captures global trends. These functions work particularly well in cases in which matching the plane in the value of the samples will not accurately represent the given surface. Compared to the GP method, the change in the shape of the isolines is noticeable, while maintaining the trend.

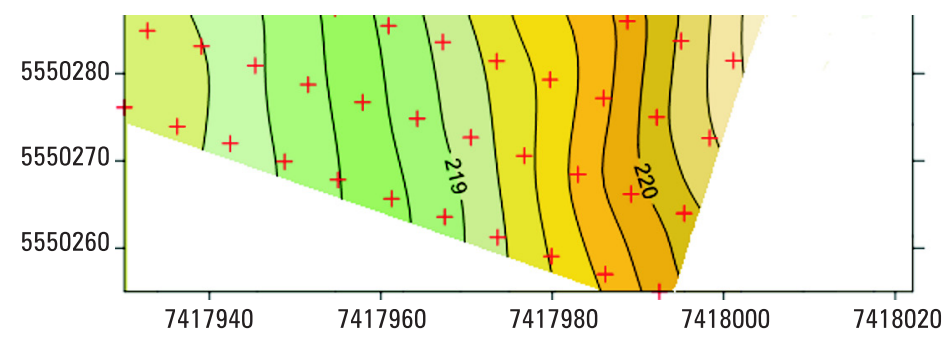

Fig. 9. An example of applying the KRIG method

The contour line has also been determined for the Kriging method. A fragment of the depiction of the terrain marked out using the Kriging method is shown in Figure 9. When comparing the isolines obtained from the KRIG and RBF methods, one should note the very high similarity between the contours.

In the second example, satellite data was used in order to produce an image of the syncline (subsidence trough) caused by underground mining exploitation. There are 
some examples in the literature, of the use of satellite imagery for large-area studies of synclines induced by mining activities [Galloway and Burbey 2011]. Remote sensing technology utilising radar imagery is relatively well documented [Malenovsky et al. 2012]. However, it was only the access to regular imagery implemented by the SENTINEL mission managed by ESA [Casu et al. 2006, Malenovsky et al. 2012], which made a comprehensive approach to determining vertical displacements in mining areas possible [Milczarek et al. 2017].

On the basis of the obtained data, interpolation of the terrain (surface) transformations was performed, using each of the methods discussed. Figure 10 shows the images of synclines (subsidence troughs) for each of the described methods.

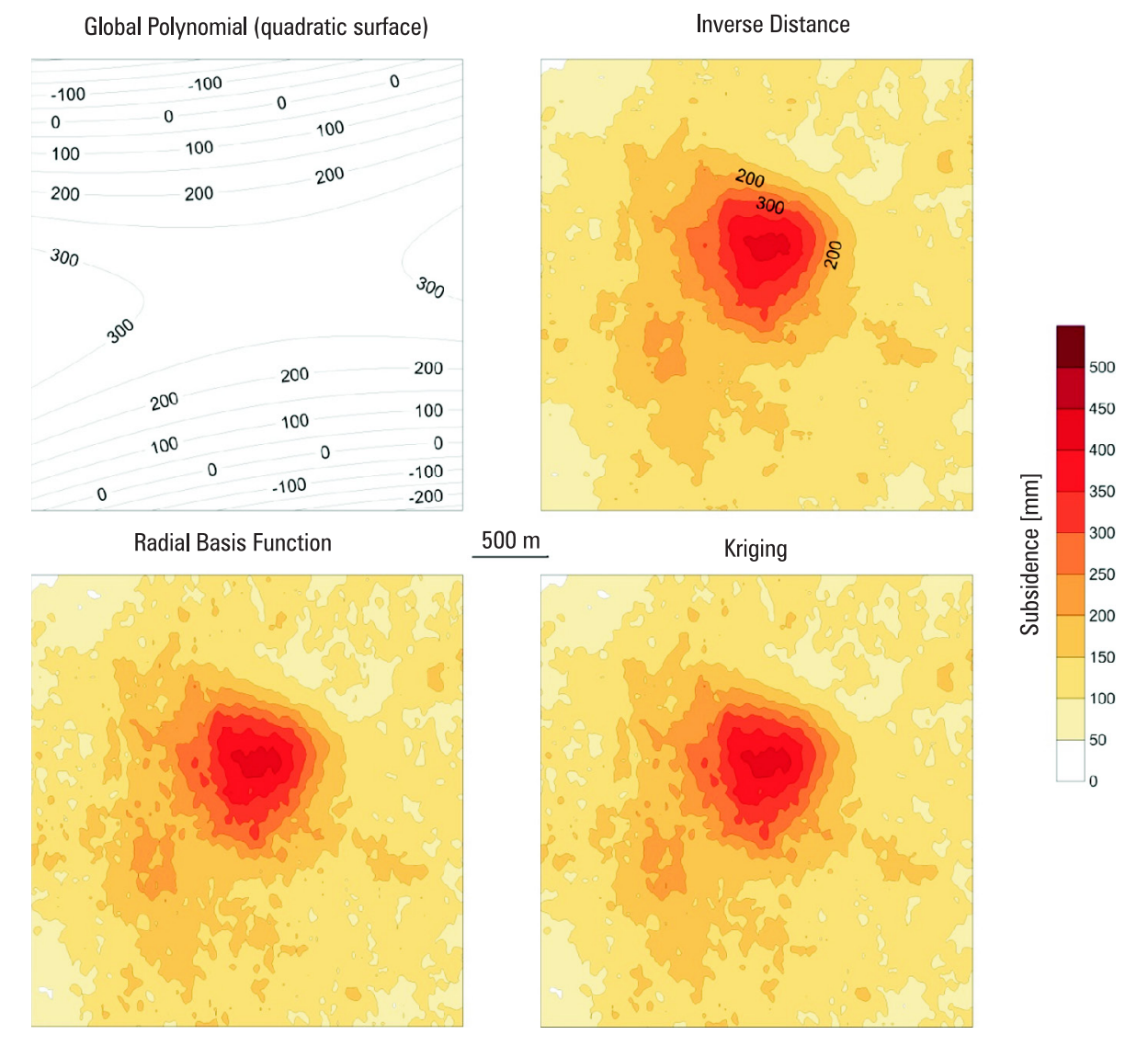

Fig. 10. Comparison of the syncline (subsidence trough) shapes interpolated using different methods 
For the analysis, the results of imaging terrain transformations (subsidence) caused by underground mining exploitation were used. Surface movements were registered by the SENTINEL mission between November 15, 2014 and October 30, 2017. From the radarogram fragments, a set of points (pixels) was obtained, for which the value of the vertical displacement was determined. The distance between the points was about $20 \mathrm{~m} .14554$ points were used for the analysis. The maximum value of the subsidence was approximately $440 \mathrm{~mm}$, which gives a subsidence rate of about $147 \mathrm{~mm}$ per year.

When analysing the obtained results, it can be concluded that the GP method does not work in such cases. The remaining three interpolation results are very similar. The result from the IDW method is displaying a greater regularity than in the case of other methods (the syncline is more "smoothed"). However, it should be stated that all of the obtained results are burned with significant random distortions.

In order to directly compare the results of interpolation with the measurement results, a profile line was extracted from the measurement set, passing through the centre of the syncline. The profile line consisted of 150 points. The line has been extracted means that these points were not included in the interpolation calculation. The results of interpolation were determined for the same profile, and they were compared with the actual measured values. The comparison between the measured values and the interpolated values is shown in Figure 11.

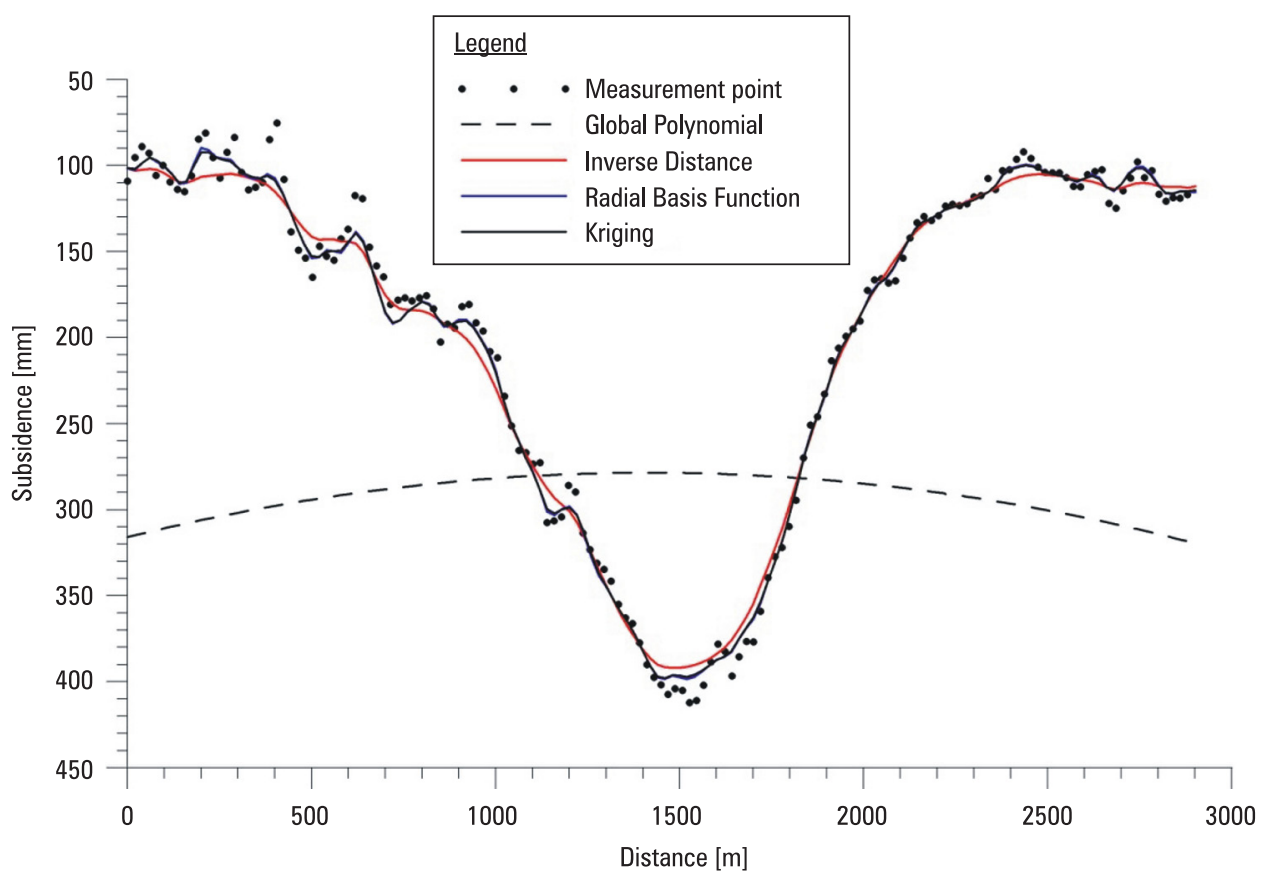

Fig. 11. Comparison of interpolation results with measurement points 
As shown in Figure 11, the results of calculations using three methods (IDW, RBF, Kriging) produce very similar results. The interpolated values of the syncline (the subsidence trough) are well matched to the measurement results. The IDW method smoothens the results, while at the bottom of the syncline, the value of subsidence is slightly lower.

\section{Conclusion}

The use of interpolation methods to create the isoline of the terrain is an issue that has been well described in the literature. There are many computational algorithms developed that operate with numerous parameters. The results of these methods, however, are not objective. There is always a factor of subjective selection of the method and the parameters within this method. Each interpolation method is used in different situations, whereas different researchers hold their own opinions about these methods.

The analyses carried out as a part of this study indicate a high similarity between the results of KRIG and RBF methods. The IDW method causes greater smoothing in relation to KRIG and RBF. However, in relation to the GP method, it should be used primarily for trend analysis.

Generally, in the Earth sciences, the Kriging method is the most commonly used, however, we must remember to perform a data analysis before its application. Such analysis should mainly include the development of a data semivariogram, in order to determine the parameters of the interpolation model. The application of automatic solutions can generate significant errors in contour interpolation and distort the image of the measurement object.

\section{References}

Berardion P. 2002. A new algorithm for surface deformation monitoring base on Small Baseline Differential SAR Interferograms. IEEE Transactions on geoscience and remote sensing, 40, 11.

Borchers J.W., Carpenter M. 2014. Land Subsidence from Groundwater Use in California. California Water Foundation Full Report of Findings, April 2014.

Burrough P., McDonnell R. 1998. Principles of Geographical Information Systems, Oxford University Press Inc., New York.

Buśko M., Frukacz M., Szczutko T. 2014. Classification of precise levelling instruments referring to the measurements of historic city centres. 9th International Conference Environmental Engineering (ICEE), May 22-23, 2014, Vilnius Gediminas Tech. Univ., Lithuania, $1-6,10$.

Carlson R.E., Foley T.A. 1991. The Parameter R2 in Multiquadric Interpolation. Computers Math. Applic., 21, 9, 29-42.

Casu F., Manzo M., Lanari R. 2006. A quantitative assessment of the SBAS algorithm performance for surface deformation retrieval from DInSAR data. Remote Sensing of Environment, 102, 3-4.

Chenoweth M.E. 2009. A numerical study of generalized multiquadric radial basis function interpolation. SIAM Undergraduate Research Online, 2. 
Childs C. 2012. Interpolating surfaces in ArcGIS Spatial Analyst, ESRI Education Services.

Davis J.C. 1986. Statistics and Data Analysis in Geology. John Wiley and Sons, New York.

Draper N., Smith H. 1981. Applied Regression Analysis, 2nd ed. Wiley-Interscience, 709.

Dwicedi R., Narayan A.B., Tiwari A., Dikshit O., Singh A.K. 2016. Multi-temporal SAR Interferometry for landslide monitoring. The International Archiver of the Photogrammetry, Remote Sensing and Spatial Information Sciences, XLI-B8, 55-58.

Franke R. 1982. Scattered Data Interpolation: Test of Some Methods. Mathematics of Computations, 33, 157, 181-200.

Galloway D., Burbey T. 2011. Review: regional land subsidence accompanying groundwater extraction. Hydrogeology Journal, 19(8).

Grzelak D., Kwinta A. 2013. A comparison of interpolation methods for flood zones adjacent to a stream. Geomatics, Landmanagement and Landscape, 3, 49-58.

Hardy R.L. 1990. Theory and Applications of the Multiquadric-BiHarmonic Method. Computers Math. Applic, 19, 8/9, 163-208.

Kokesz Z. 2010. Sporządzanie map izoliniowych procedurą krigingu zwyczajnego - korzyści i ograniczenia. Zeszyty Naukowe Instytutu Gospodarki Surowcami Mineralnymi i Energią Polskiej Akademii Nauk, 79, Kraków.

Magnuszewski A. 1999. GIS w geografii fizycznej. Wydawnictwo Naukowe PWN, Warszawa.

Malenovský Z., Rott H., Cihlar J., Schaepman M.E., García-Santos G., Fernandes R., Berger M. 2012. Sentinels for science: Potential of Sentinel-1,-2, and-3 missions for scientific observations of ocean, cryosphere and land. Remote Sens. Environ., 120, 91-101

Marmol U. 2002. Modelowanie reprezentacji powierzchni topograficznej z wykorzystaniem metody geostatystycznej, Geodezja 8 (2), 259-270.

Milczarek W., Blachowski J., Grzempowski P. 2017. Wykorzystanie satelitarnej interferometrii radarowej w badaniach deformacji powierzchni w górnictwie odkrywkowym węgla brunatnego. Górnictwo Odkrywkowe, 1.

Mongillo M. 2011. Choosing Basis Functions and Shape Parameters for Radial Basis Function Methods. SIAM Undergraduate Research Online (SIURO), 4.

Mulugeta G. 1999. The elusive nature of expertise in spatial interpolation. Cart. Geog. Inf. Sys., 25 (1), 33-41.

Namysłowska-Wilczyńska B. 2006. Geostatystyka. Teoria i zastosowanie. Wyd. Politechniki Wrocławskiej, Wrocław.

Ralston A. 1965. First Course in Numerical Analysis. McGraw-Hill, New York.

Robeson S.M. 1997. Spherical methods for spatial interpolation: Review and evaluation, Cartog. Geog. Inf. Sys., 24 (1), 3-20.

Sarra S.A. 2009. Radial basis function interpolation. Submitted to SIURO.

Sauer T. 2006. Numerical Analysis. Pearson Education, Inc., Boston.

Szubert M. 2003. Cyfrowy model wysokości powierzchni podczwartorzędowej na wyżynie woźnicko-wieluńskiej. Archiwum Fotogrametrii, Kartografii i Teledetekcji, Wrocław, 13A, 233-242.

Wackernagel H. 2003. Multivariate geostatistics. An introduction with applications, 3rd ed. Springer-Verlag, Heidelberg.

Watson D.F. 1992. Contouring: A guide to the analysis and display of spatial data. Oxford, Pergamon.

Wilson J.P. 2012. Digital terrain modeling. Geomorphology, 137, 1, 107-121.

Zawadzki J. 2011. Metody geostatystyczne dla kierunków przyrodniczych i technicznych. Oficyna Wyd. Politechniki Warszawskiej, Warszawa. 
Zhao R., Li Z., Fend G., Wang Q., Hu J. 2016. Monitoring Surface deformation over permafrost with an improved SBAS-InSAR algorithm: Wits emphasis on climatic factors modeling. Remote Sensing of Environment, 184, 276-287.

\author{
Dr inż. Robert Gradka \\ Politechnika Wrocławska \\ Wydział Geoinżynierii, Górnictwa i Geologii \\ 50-421 Wrocław, ul. Na Grobli 15 \\ e-mail: robert.gradka@pwr.edu.pl \\ Dr hab. inż. Andrzej Kwinta, prof. nadzw. \\ Politechnika Wrocławska \\ Wydział Geoinżynierii, Górnictwa i Geologii \\ 50-421 Wrocław, ul. Na Grobli 15 \\ e-mail: Andrzej.kwinta@pwr.edu.pl
}

